\title{
El origen de la secta del mar Muerto a la luz de 4QMMT
}

\author{
César Vidal Manzanares
}

Cuando en 1948 se produjo el descubrimiento de los escritos del mar Muerto ${ }^{1}$, poco se podia sospechar que se entraba en un período de investigación que, en relación con las cuestiones esenciales del hallazgo, distaria mucho de poder considerarse esclarecida incluso después de más de cuatro décadas. Aún más, menos se intuía que al cabo de ese tiempo todavía algunos de los documentos no habrian salido de las sombras de su versión original para ser publicados primero, traducidos después y hechos objetos de la discusión científica finalmente.

Esta circunstancia ligada al hecho de la cercanía geográfica de los manuscritos del mar Muerto con el judaísmo del Segundo Templo y con los orígenes del cristianismo ha tenido como fruto, entre otras cosas, una especulación sobre la teologia, la identificación, el origen y la historia del grupo conservador de los mismos, que, en muy pocos aspectos, puede decirse que pise terreno firme. Sólo la publicación progresiva de hallazgos que llevan a sus espaldas décadas de haber visto la luz va desbrozando de imaginaciones calenturientas la investigación en torno a la secta del mar Muerto y arrojando claridad sobre aspectos esenciales de la misma.

1 Sobre el hallazgo de los manuscritos véase: DE VAUX, R., Archaeology and the Dead Sea Scrolls, Londres, Clarendon, 1973, y SUKENIK, E. L., Meguillot genuzot mi-Midbar Yehudah. Jerusalén. Bailik, 1948 y 1950 (en hebreo). Para un relato en castellano de este episodio cf.: Gonzalez LamadRID, A., Los descubrimientos del mar Muerto. Madrid, BAC, 1985, págs. 21-116, y VERMES, G., Los manuscritos del mar Muerto. Barcelona, Muchnik, 1987 (3. ${ }^{a}$ ed.), págs. 9-24. 
Sin lugar a dudas, uno de estos pasos adelante va a venir determinado, a nuestro juicio, por la publicación del documento 4QMMT. Este documento establece de manera definitiva el origen ideológico de los miembros de la secta del mar Muerto y, con menor seguridad, la época de su nacimiento como grupo. Con ello queda clarificado, al menos parcialmente, el contenido original teológico de la secta y cabe la posibilidad de que eso permita aproximarnos al problema de su identificación sobre bases más firmes. En este artículo pasaremos revista a las distintas teorias sobre el origen de la secta de Qumran y, posteriormente, analizaremos cómo se ven en mayor o menor medida, alteradas a la luz de la publicación del documento $4 \mathrm{QMMT}$.

\section{LA TESIS JUDEO-CRISTIANA}

Para hacer honor a la verdad hay que reconocer que pocos temas han resultado más controvertidos en el marco del periodo histórico del Segundo Templo que el esclarecimiento de la identificación y el origen de la secta religiosa relacionada con los manuscritos del mar Muerto. Era de esperar, por lo tanto, que en ocasiones con dudosa profesionalidad se crearan teorias que despreciaban o bien el análisis paleográfico de los documentos o bien la evidencia interna que éstos ofrecian. No resultaba tampoco extraño que, a la vez, se intentara enlazar el hallazgo con corrientes espirituales que, aun hoy en dia, conservan un evidente poder de atracción o con las que se podían establecer paralelos. Por ello, era de esperar que, desde el principio, la secta del mar Muerto fuera identificada con un grupo judeo-cristiano.

Inicialmente tanto J. L. Teicher ${ }^{2}$ como G. Margolirouth ${ }^{3}$ abogaron por una identificación de este tipo, si bien, como veremos, las conclusiones a las que llegaron distaban mucho de asemejarse ${ }^{4}$. Para el primero

${ }^{2}$ Sobre la tesis judeo-cristiana en J. L. Teicher veáse TEICHER, J. L., "The Damaskus fragments and the Origin of the Jewish Christian Sect", Journal of Jewish Studies, num. 2 , 1951, págs. 115-143; idem, "The Teaching of the pre-Pauline Church in the Dead Sea Scrolls", Journal of Jewish Studies, núm. 4, 1953, págs. 1-13.

${ }^{3}$ Cf. Margououth, G., "The Two Zadokites Messiahs". Journal of Theological Studies, núm. 12, 1911, págs. 446-459.

4 En relación con el judeo-cristianismo véase Fernandez Uriel. Pilar, y Vidal ManzanaRES, Cesar, "Anavim, apocalipticos y helenistas". Homenaje a José María Blázquez. Madrid (en prensa). 
el Maestro de Justicia seria Jesús y el Sacerdote Impío debería identificarse con Pablo de Tarso. A favor de esta tesis se alzaba el hecho de que ciertamente se dan paralelos ideológicos entre la misma y el sistema de pensamiento de algunos grupos existentes en el seno del judeocristianismo ${ }^{5}$, como es el caso de los ebionitas ${ }^{6}$. Para el segundo, el Mesías de Aarón y de Israel sería Juan el Bautista, mientras que Jesús sería el Maestro de Justicia.

La tesis, en sus diversas manifestaciones, quedó refutada ampliamente por A. Dupont-Sommer ${ }^{7}$, pues no deja de ser claro, a la luz de los documentos, que el Maestro de Justicia no puede identificarse con Jesús y que Pablo difícilmente puede ser el Sacerdote Impío, puesto que no pertenecia a la casta sacerdotal, sino a la tribu de Benjamin ${ }^{8}$.

\section{LA TESIS CARAITA}

Formulada en 1949, al poco de descubririse los manuscritos, y defendida inicialmente por S. Zeitlin ${ }^{9}$, apuntaba a un origen medieval y caraíta de los escritos de Qumran. De esta manera, el Documento de Damasco sería un ufraude pío" destinado a demostrar el origen antiguo de los caraitas. Con el tiempo ha resultado admisible la tesis de una relación teológica entre los sectarios de Qumran y los caraitas ${ }^{10}$, pero la idea de un origen medieval de los escritos de Qumran se viene abajo simplemente con el análisis paleográfico de los mismos. De ahi que la

${ }^{5}$ Cf. Meeks, Wayne A. (editor), The writings of St. Paul. New York, W. W. Norton and Company, 1972, págs. 176-184

- Personalmente coincido con la tesis de Grego, I., I Giudeo-Cristiani nel IV secolo. Jerusalén, FPP, 1982, en el sentido de que los judeo-cristianos eran doctrinalmente ortodoxos en sus concepciones teológicas, salvo en el aspecto relativo a la vigencia de la Torah. Por ello, habria que considerar a los ebionistas más como una secta herética entre los judeo-cristianos que como un exponente representativo de los mismos.

Dupont-SOMmeR, A., Les écrits esséniens découverts près de la Mer Morte. Paris, 1959, págs. 406-408.

${ }^{8} \mathrm{Cf}$. al respecto Fitipenses 3: 5. Cabe la posibilidad de que esta circunstancia explique el nombre hebreo del Apóstol de los Gentiles, que coincide con el del primer monarca de Israel, que también procedia de la tribu de Benjamin; vid. I SAMUEL 9: 1-2.

${ }^{9}$ Vease ZEITLIN, S., "The Zadokite fragments", Jewish Quarterly Review. Monograph, Series núm. 10. Filadelfia, 1952, págs. 5-23; idem, The Dead Sea Scrolls and Modern Scholarship. Filadelfia, 1956.

${ }^{10}$ Cf. WIEDEr, N., The Judaean Scrolls and Karaism. Londres, 1962. 
refutación de la tesis de Zeitlin por parte de $R$. de Vaux resultara, en el fondo, tan sencilla" ${ }^{"}$.

\section{LA TESIS SADUCEA}

La identificación de los sectarios de Qumran con los saduceos ha sido sostenida por R. North y A. M. Habermann ${ }^{12}$.

Aunque las diferencias entre lo que conocemos de los saduceos y los sectarios del mar Muerto en una fase desarrollada son evidentes y no permiten identificar a los dos grupos de manera automática, no puede descartarse «a priori», como se ha hecho frecuentemente, toda relación entre ambos colectivos. El carácter sacerdotal, fuertemente conservador, y su asociación con el clero sadoquita son factores difícilmente explicables sin aceptar la idea de algún contacto más que superficial. Desde nuestro punto de vista, quizá el énfasis de North y de Habermann resultó erróneo al tratar de insistir en una identidad de los dos grupos en lugar de rastrear un posible origen común. Cabe, pues, señalar que los sectarios de Qumran no eran ya saduceos en una fase de consolidación ideológica de la secta, pero, como veremos, sus fundadores procedian de los mismos. Sobre esta cuestión volveremos más adelante ${ }^{13}$.

\section{LA TESIS ZELOTA}

De mayor predicamento, aunque de menos base, desde nuestro punto de vista, gozó la teoría de identificar a la secta con los zelotes o zelotas. Ya antes de los descubrimientos de Qumran, el P. Lagrange se

Cf. De Vaux, R., Revue Biblique, núm. 64, 1957, págs. 636-736.

12 Cf. NORTH, R., "The Qumran Sadducees", Catholic Biblical Quarterly, núm. 17, 1955 , págs. 164-188, y Habermann, A. M., Los manuscritos del desierto de Judá, 1959, Tel Aviv (en hebreo).

${ }_{13}$ Un estudio, desde nuestro punto de vista, colmado de interés sobre la posible relación entre saduceos y sectarios del mar Muerto es el realizado por BAUMGARTEN, J. M., "The Pharisaic-Sadducean Controversies about Purity and the Qumran Texts", Journal of Jewish Studies, núm. 31, 1980, págs. 157-170. 
mostró partidario de identificar a los sectarios del documento de Damasco con los zelotes ${ }^{14}$.

Sobre una base muy similar, C. Roth ${ }^{15}$ y G. R. Driver ${ }^{16}$ defendieron la identidad zelote de la secta del mar Muerto. Para el primero, el Maestro de Justicia sería Menahem ben Judá, uno de los caudillos zelotes de la guerra contra Roma (66-73 d.C). Su muerte habria que situarla en el año 66 d.C. cuando como consecuencia de un enfrentamiento con el "Sacerdote Impio", Eleazar ben Hananía, que era capitán de los guardias del Templo, sus seguidores fueron dispersados y el propio Menahen ben Judá fue ejecutado sumariamente en la colina del Ofel.

G. R. Driver articuló una tesis zelote mucho más elaborada que la de Roth y creemos que, aunque insostenible en bloque, contiene algunos elementos de verosimilitud. También para él, el trasfondo histórico de los rollos se encuentra en la guerra contra Roma (66-73 d.C). Los sectarios de Qumran procederian del cisma sadoquita que, por otro lado, también daría nacimiento a los saduceos. Volvemos, pues, a la tesis de un origen común para saduceos y sectarios del mar Muerto, sobre la que aún hemos de incidir más adelante y que, desde nuestro punto de vista, tiene todas las posibilidades de ser cierta.

G. R. Driver, no obstante, no se limitaba a apuntar este origen común, sino que trazaba luego una línea evolutiva de la historia de los sectarios que, a nuestro juicio, es menos probable. Así, el grupo desgajado con ocasión del cisma sadoquita huiria a Egipto hacia el 170 a.C. con Onías IV, de donde regresaría a Jerusalén, aceptando la jefatura del sacerdote Boecio, tras la intervención pompeyana. Con posterioridad, el liderazgo de Boecio se vería cuestionado y sus seguidores se colocarian bajo el mando de Judas el galileo, uno de los presuntos fundadores de los zelotes ${ }^{17}$. Tras la muerte de Judas el 6 d.C., estos zelotes se trasladarian a Qumran. Driver realiza, además, una identificación del Maestro de Justicia y del Sacerdote Impío similar a la de Roth.

14 Lagrange, J. M., Le judaïme avant Jésus-Christ. Paris, 1931, págs. 330-337. Anteriormente este mismo autor habia negado tal posibilidad; cf. ídem, "La secte juive de la Nouvelle Alliance au pays de Damas", Revue Biblique, núm. 9, 1912, págs. 321-330.

${ }^{15} \mathrm{Cf}$. Roth, C., The Historical background of the Dead Sea Scrolls. Oxford, 1958.

${ }^{16} \mathrm{Cf}$. Driver, G. R., The Judaean Scrolls. The problem and a Solution. Oxford, 1965.

17 Aunque la tesis más extendida pretende retrotraer a los zelotes a la época de Judas el galileo, insistiendo en que luego el grupo mantuvo su existencia de manera ininterrumpida hasta la guerra con Roma, creemos que esta opinión es insostenible a la luz de las fuentes históricas y, principalmente, Josefo. 
Ya hemos señalado que la teoría de Driver está mucho mejor articulada que la de Roth, no obstante su desprecio por los datos arqueológicos, que indican una ocupación continua de Qumran desde el siglo ॥ a.C. hasta el 68 d.C., la convierten en parejamente insostenible. Así lo supo señalar De Vaux ${ }^{18}$, a nuestro juicio, de manera irrefutable.

\section{LA TESIS FARISEA}

Al igual que sucedió con la tesis zelote, la atribución de una identidad farisea al Documento de Damasco ya había sido formulada antes de los descubrimiento del mar Muerto. Con posterioridad a éstos se han producido varios intentos encaminados a demostrar una identidad entre los sectarios del mar Muerto y los fariseos ${ }^{19}$. Tanto A. Dupont-Sommer como R. de Vaux ${ }^{20}$ refutaron en su dia tal posibilidad con argumentos que, desde nuestro punto de vista, continúan siendo definitivos. Entre ellos cabe destacar el hecho de que los fariseos constituian una secta fundamentalmente laica, mientras que la del mar Muerto era sacerdotal, que el calendario de los fariseos era lunar, mientras que el de los sectarios de Qumran era solar, etc.

\section{LA TESIS ESENIA}

Hoy por hoy, ésta es la teoria mayoritariamente aceptada en relación con la identidad de los sectarios del mar Muerto. El primero en señalar tal posibilidad fue E. L. Sukenik, pero el mérito de su difusión se debe

${ }^{18} \mathrm{Cf}$. DE VAUX, R., "Esséniens ou Zélotes? 'A propos d'un livre récent", Revue Biblique, núm. 73, 1966. págs. 212-235. A esto respondió G. R. Driver en dos ocasiones, si bien no añadia nada sustancialmente nuevo a la controversia que permanecia zanjada, cf. DRIVER, G. R., "Myths of Qumran", Annual of Leeds University Oriental Society, núm. 6, 1966-68, págs. 23-40, e idem, "Mythology of Qumran", Jewish Quarterly Review, núm. 71, 1970. págs. 241-281.

${ }_{19}$ Cf. RABIN, CH., Qumran Studies. Scripta Judaica II. Londres, 1957. 127-128.

Cf. Dupont-Sommer, obra citada, págs. 415-420, y DE VAUX, R., obra citada, págs. 
mayormente a Dupont-Sommer ${ }^{21}$. En términos generales, los esenios parecen ser el grupo que resulta más fácil de identificar con los sectarios de Qumran, pero no debería olvidarse, como se hace a menudo, que existen también notables diferencias si contrastamos ambos colectivos a la luz de lo recogido por Flavio Josefo. Explicar esto recurriendo al hecho de que Flavio Josefo quizá no conoció toda la evolución doctrinal de la secta puede resultar funcional, pero no es, desde nuestro punto de vista, definitivo ${ }^{22}$. El mismo De Vaux reconoció la falta de base arqueológica para sustentar tal teoria ${ }^{23}$. Sin ánimo de dogmatizar, creemos que en la identificación ha pesado mucho, consciente o inconscientemente, el deseo de que los sectarios de Qumran pudieran ser identificados con alguna de las sectas descritas por Josefo. Por procedimiento eliminatorio, al que se unen algunos aspectos de similitud, parecería así más aceptable la posibilidad de que los esenios fueran el mismo colectivo religioso que los sectarios del mar Muerto, pero, a nuestro juicio, afirmar esto dogmáticamente no está justificado en el estado actual de nuestros conocimientos.

\section{LA TESIS MIXTA DE THIERING}

Un elemento de novedad en la identificación de la secta de Qumran fue introducido hace unos años por el trabajo de una erudita australiana, B. E. Thiering, en el que se pretendía demostrar el paso de los sectarios por diversas fases teológicas ${ }^{24}$. Inicialmente, la secta habría sido esenia para luego convertirse en zelote, judeo-cristiana y, finalmente, zelote. EI Maestro de Justicia sería Juan el Bautista y el Sacerdote Impío, Jesús de

21 Por extraño que pueda parecer, en términos generales, el Documento de Damasco no habia sido relacionado con los esenios salvo de manera excepcional y, presuntamente indecisa; cf. GinzBERG, L., "An Unknown Jewish Sect". Moreshet, series núm. 1. Nueva York, 1976 (traduccion de Eine unbekannte jüdische Sekte. Nueva York, 1922), y LEVI, I., Revue des études juives, núm. 62, 1912

22 En contra, Delcor, M., y Garcia Martinez, F., Introducción a la literatura esenia de Qumran. Madrid, Cristiandad, 1982, págs. 33-35. Sobre las concomitancias juridicas entre los esenios de Josefo y los sectarios de Qumran cf. Delcor, M., Le vocabulaire juridique, cultuel et mystique de linitiation dans la secte de Qumrâm en Qumran-Probleme. Berlín, Ed. H. Bardtke, 1963, págs. 109-134. No obstante, la argumentación de Delcor dista mucho, a nuestro juicio, de ser definitiva.

${ }^{23}$ Cf. DE VAUX, R., obra citada, pág. 126.

${ }^{24}$ Cf. THIERING, B. E., "Redating the Teacher of Righteousness", Australian an New Zealand Studies in Theology and Religion, núm. 1, Sydney, 1979. 
Nazaret. De esta manera, los escritos del mar Muerto vendrían a mostrar otra visión de las relaciones entre Juan y Jesús diversas a las contenidas en el Nuevo Testamento ${ }^{25}$. El cisma en la secta vendria a ser la división de la misma al seguir la mayoría de sus miembros a Jesús ${ }^{26}$.

La tesis de Thiering se ve desmentida por el análisis paleográfico de los textos, pero plantea una nueva hipótesis de trabajo no explotada hasta la fecha. La de aceptar alteraciones considerables en el contenido teológico de los sectarios a lo largo de su ocupación de Qumran. Aunque no parece haber elementos que justifiquen tal hipótesis, quizá resultaría interesante abordarla como instrumento de investigación futura.

\section{LOS NUEVOS DATOS PROPORCIONADOS POR EL DOCUMENTO $4 Q M M T$}

Un nuevo elemento ha venido a sumarse recientemente a los ya existentes para esclarecer el origen y la identificación de los sectarios de Qumran. Nos estamos refiriendo al documento 4QMMT o Miqshat Ma'aseh Ha-Torah. Preservado en seis manuscritos, tiene la pretensión de ser una carta enviada por uno o varios miembros de la secta naciente a un grupo de los dirigentes, seguramente sacerdotales, de Jerusalén. En el cuerpo del documento se hace una referencia a una veintena de disposiciones legales referentes a la ley relativa a los sacrificios, las ofrendas sacerdotales, la pureza ritual, etc. Todas las referencias legales constituían puntos de discrepancia entre los sectarios y los sacerdotes de Jerusalén, y así lo deja claramente establecido el documento.

Aunque no podemos señalar categóricamente si se trataba de una carta real o de un documento redactado «a posteriori" para justificar la ruptura con la clase sacerdotal jerosimilitana, lo que sí resulta indiscutible,

${ }^{25}$ Acerca de las relaciones entre Jesús y Juan en las fuentes neotestamentarias véase: Mateo 3: 1-17; Marcos 1: 1-8; LuCAS 3: 1-18; JuAN 1: 19-36. Las fuentes del Nuevo Testamento parecen haber conservado algunas referencias a dudas del Bautista sobre la mesianidad de Jesús; vg. Mateo 11: 2-3; LUCAS 1: 18-23.

${ }^{26}$ Parece indiscutible que algunos de los discipulos de Juan siguieron a Jesús; vg. JUAN 1: 35 ss., pero no deja de ser significativo que el Evangelio que señala esto con más claridad, el de Juan, sea el que más patentemente subraye la sumisión del Bautista a la figura de Jesús. En torno a este tema cf. Cullmann, O., The Christology of the New Testament. Londres, SCM, 1975, págs. 23 ss. 
a tenor de los ejemplares conservados, es que los sectarios de Qumran tenian el escrito en gran consideración.

\section{A) La estructura y el contenido del texto}

El texto admite una división ideal en tres partes: una introducción, una sección halájica en la que se expresan las discrepancias con el bando jerosimilitano y una conclusión. En uno de los manuscritos el texto aparece reproducido a continuación de un calendario solar de 364 días ${ }^{27}$. La carta no contiene ninguna designación propia y el título Miqshat Ma'aseh Ha-Torah procede de la descripción de su contenido en la conclusión.

a) La introducción. - La frase inicial señala que el contenido del documento son "palabras nuestras" que constituyen "normas legales" (ma'asim). A tenor de lo expuesto en el texto, estas reglas van referidas a dos temas. El primero se desarrollaba en una laguna del texto y el segundo era relativo a los "rituales de purificación". En opinión de Schiffman ${ }^{28}$ en la laguna del texto podría aparecer algún término como "matanot» (ofrendas para el templo y los sacerdotes) o "qorbanot" (sacrificios). Cabe tal posibilidad, pero, momentáneamente, no pasa de serlo.

b) Las discrepancias.-En esta parte del documento aparecen recogidas una veintena de normas legales. Teóricamente fue la interpretación de las mismas la causa directa del cisma que hizo nacer la secta del mar Muerto. Aquí descansa, a nuestro juicio, uno de los elementos de análisis relativos al origen de la secta. Ésta no acabó separada del judaismo del Segundo Templo por creer en un Mesias concreto (como fue el caso del judeo-cristianismo), sino por cuestiones relativas a la interpretación de la Torah y, fundamentalmente, al servicio del Templo. De hecho, otras sectas, como fariseos y saduceos, aunque difiriendo entre sí, mucho más que los sectarios del mar Muerto de los saduceos, por ejemplo,

${ }^{27}$ Sobre el calendario solar de la secta cf. TALMON, S., "The Calendar Reckoning of the Sect from the Judaean Desert», en The World of Qumran from within, 1989, Jerusalen, Magnes, págs. 157-85.

${ }^{28}$ Cf. SCHIfFMan LAWrence, H., "The New Halakhic Letter (4QMMT) and The Origins of the Dead Sea Sect", Biblical Archaeologist., junio 1990, Baltimore, págs. 64-73. 
no abandonaron la unión en el seno de un judaísmo centrado en el Templo común de Jerusalén.

c) La conclusión.-En esta parte del texto se señala que precisamente la obediencia a las normas recogidas en la sección anterior es lo que ha provocado la separación de los sectarios. "Nos hemos separado" (parashnu) del "común del pueblo" (rov ha-'am), afirma taxativamente el texto, indicando así la retirada de la práctica de los rituales tal y como los realizaba la mayoría de la nación. No se trata además de un grupo que acepte la idea de una flexibilización de los diversos rituales (como era el caso del judeo-cristianismo), sino que nos encontramos ante una secta de escrupuloso cumplimiento, aunque distinto, según les constaba a los destinatarios del documento (we-'attem).

Lo que pide el autor, o autores, es que los receptores investiguen cuidadosamente el Libro de Moisés (seguramente la Torah), los Profetas y a David, así como la historia de las generaciones, a fin de descubrir dónde se han desviado del correcto cumplimiento de las normas ${ }^{29}$. Arrancando de adaptaciones de citas del Deuteronomio (31: 29 y 30: 12) y de algunos ejemplos históricos del período de la monarquía, el autor o autores de la carta indican las bendiciones o maldiciones que se desprenden de un cumplimiento correcto o incorrecto de las normas a la vez que indican que están viviendo en la época en que Israel experimenta el llamado a arrepentirse en lugar de apartarse.

Finalmente, se indica la razón por la que se ha enviado la carta y aquí es donde aparece la expresión "Miqshat Ma'aseh Ha-Torah" en el sentido de "reglas relativas a la Torah". Se insiste en que el receptor de la carta es sabio y conoce lo bastante de la Torah como para entender correctamente los asuntos tratados en el documento, resultando en beneficio de él y de la nación de Israel su sumisión a tal enfoque.

\section{B) El receptor del documento}

Surge, por supuesto, la cuestión de quién era el receptor del documento. La dificultad principal estriba en el hecho de que el propio docu-

${ }^{29}$ Quizá pueda ser ésta una referencia a un canon tripartito del Antiguo Testamento, pero no nos parece que resulte tan claro. También, por ejemplo, podría tratarse de basar la argumentación no sólo en Torah, sino también en otras fuentes sin reconocerles, necesariamente, un papel canónico. 
mento alterna el singular ('eleja, en la parte introductoria) con el plural ('attem, en la lista de disposiciones legales). Una vez que se concluye la enumeración jurídica, el texto vuelve al singular. ¿Quién era el receptor del mensaje?

Schiffman ${ }^{30}$ ha abogado por la identificación del mismo con un sumo sacerdote hasmoneo, lo que explicaría las referencias a los monarcas del Israel antiguo: sabido es que los hasmoneos aparecieron en sus monedas como monarcas y que desempenaron funciones de este tipo. El documento precederia, además, a la aparición del Maestro de Justicia. Por el contrario, Quimron y Strugnell ${ }^{31}$ han identificado al receptor con un enemigo del Maestro de Justicia que podria ser Jonatán o Simón. Ninguna de las dos respuestas soluciona, desde nuestro punto de vista, la aparente contradicción en el seno mismo de la carta.

Tal contradicción desaparece si aceptamos la posibilidad, correcta a nuestro modo de ver, de que el destinatario sea un colectivo al que, en algunos momentos, el autor se dirige en singular personificándolo.

La posibilidad de que los personajes protagonistas de los Documentos de Qumran sean colectivos ya ha sido apuntada anteriormente ${ }^{32}$ y creemos que, aunque no sea aceptada mayoritariamente, es fundamentalmente correcta. Por lo tanto, el documento estaría dirigido a un ente colectivo, al que, lógicamente, se designa unas veces en singular y otras en plural, al que se consideraba conocedor de la Torah y con capacidad para imponer sus decisiones tanto política como religiosamente. Creemos que tal colectivo era la casta sacerdotal controlada por los hasmoneos, pero en una época de predominio fariseo. Examinemos en qué basamos tal conclusión.

Para empezar diremos que la veintena de normas en disputa se asemeja considerablemente a los polos presentados en la literatura rabínica por fariseos y saduceos. En este caso, los oponentes de los cismáticos reproducen precisamente la interpretación de los fariseos. Por el

${ }^{30}$ Cf. Obra citada, pág. 67.

${ }^{31}$ Quimron, E., y StRugnell, J., "An Unpublished Halakhic Letter from Qumran", Biblical Archaeology Today, 1985, Jerusalén, Israel Exploration Society, págs. 400-7.

${ }^{32}$ Asi, en el pésher de Habacuc, el "Sacerdote Impío" no corresponde a un personaje sólo, sino a un colectivo cronológico. Cf. VAN DER WOUDE, "De Tempelrod van Qumrân," Nederlands Theologisch Tijdschrift, núm. 34, 1980, págs. 177-190, e idem, "Wicked Priest or Wicked Priest? Reflections on the Identification of the Wicked Priest", in the Habakkuk Commentary, núm. 32, 1982, págs. 349-359. Para una ampliación de este aspecto al caso de todos los "protagonistas" de la historia de la secta cf. GASTER, T. H., The Dead Sea Scriptures, 1976, Nueva York, Anchor, págs. 27 ss. 
contrario, el punto de vista de los saduceos, tal y como se recoge en los textos taníticos, es el mismo que el de los sectarios de Qumran ${ }^{33}$ en este documento. Tal y como se presenta la evidencia la única posibilidad razonable es aceptar que los fundadores de la secta del mar Muerto, en el momento de producirse el cisma, eran saduceos.

Estos saduceos se resintieron de manera especial de los cambios introducidos en el funcionamiento del sacerdocio con el entronizamiento de los hasmoneos. El papel de los sadoquitas-saduceos se vio mermado y además sus interpretaciones en cuestiones jurídico-religiosas fueron despreciadas y hechas a un lado. Algunos de los saduceos-sadoquitas decidieron escindirse del pueblo de Israel (que se había apartado tan escandalosamente del verdadero ritual del Templo, desde su punto de vista) y retirarse al desierto. Conservaron empero la idea del valor del sacerdocio sadoquita y de ahí la insistencia que se da en los documentos de la secta en cuanto a los "hijos de Sadoq".

Esto explicaria también por qué los autores del documento presuponen un conocimiento suficiente en los receptores del mismo. Lo que no les resultaría tolerable sería la existencia de saduceos "colaboracionistas" en Jerusalén y la sumisión hasmonea a los fariseos. Que tales circunstancias sólo podían implicar el desastre para Israel estaba para los cismáticos fuera de duda y, por ello, la única salida posible era un arrepentimiento en línea con su interpretación particular de los preceptos legales.

\section{C) La datación}

¿Cuándo, pues, podríamos fechar el documento al que nos estamos refiriendo? Indudablemente nos encontramos ante un documento enraizado en los orígenes de la secta del mar Muerto. En favor de tal conclusión podemos aducir varias razones. En primer lugar, parece existir una esperanza de arreglo entre ambas partes, algo difícil de concebir cuando el movimiento no radicalizó y sectarizó más adelante. El autor o autores

${ }^{33}$ Un antecedente de esto en Baumgarten, J. M., "The Pharisaic-Sadducean controversies about Purity and the Qumran texts", Journal of Jewish Studies, núm. 31, 1980, págs. 157-70. En el mismo sentido se han pronunciado Schiffman, L. H., obra citada, y SusSman, Y., en un artículo aparecido en hebreo en Tarbiz que será incluido en la traducción al inglés de $4 Q M M T$ de Quimron y Strugnell. 
de la carta no se dirigen a enemigos, sino a antiguos compañeros de los que esperan que entren en razón. Tal posibilidad resultaría impensable sólo unos años después. En segundo lugar, en el documento existen diferencias con el Rollo del Templo (aprox. 100-125 a.C.) en el sentido de una menor rigidez, lo que viene a indicar una fecha anterior al mismo. Sea o no el Rollo del Templo obra del Maestro de Justicia, lo cierto es que es uno de los documentos primeros en la historia de la secta; luego $4 Q M M T$ ha de situarse cronológicamente en los primeros balbuceos históricos de ésta.

Por todo ello y sin deseo de dogmatizar, creemos que se puede señalar como fecha hipótetica de la redacción del Documento y, aproximadamente, del nacimiento de la secta, el reinado de Simón o, más posiblemente, el de Juan Hircano. Examinemos el por qué de esta tesis.

En ambos reinados los monarcas ostentaron la responsabilidad dual de Nasi (principe) y de Kohen Gadol (Sumo Sacerdote). Juan Hircano además fue causa de ciertos cambios en materia religiosa que no eran favorables al punto de vista de los sectarios de Qumran, pero que tampoco se inclinaban del todo hacia el punto de vista de los fariseos ${ }^{34}$. De ser cierta nuestra tesis nos encontrariamos ante una división dentro del seno de los saduceos entre un ala intransigente que marchó al desierto y otra más dada a la componenda que permaneció en Jerusalén con la esperanza de ganar la batalla a los fariseos. La primera, fundadora de la secta del mar Muerto y origen del documento que estudiamos, se radicalizó progresivamente hasta convertirse en enemiga del resto del pueblo de Israel. Es muy posible que tal radicalización viniera marcada, al menos en parte, por la aparición del maestro de justicia primero y, con ello, estariamos de acuerdo con el punto de vista de Schiffman, que data el documento antes del mismo. La segunda, a la que vulgarmente se denomina saduceos, desarrolló una labor de zapa que tuvo como fruto el que Juan Hircano se inclinara al final de su reinado en favor suyo, en detrimento de los fariseos. El cisma, a esas alturas, era irreversible y no hubiera tenido sentido en esa época la redacción del documento al que nos estamos refiriendo.

Abona, además, esta tesis el hecho de que fue precisamente durante el período de Juan Hircano cuando se estructura el conjunto de las construcciones de Qumran de manera definitiva. Al lado del sistema de servicio de agua aparece una configuración de restos arqueológicos que nos

${ }^{34} \mathrm{Cf}$. Friedner, Y., History of the Jewish Temple: The Second Temple Era, 1986, Nueva York, Mesorah, págs. 88 ss. 
permite pensar en una comunidad. Este período, denominado $\mathrm{lb}$, concluye en los comienzos del reinado de Herodes el Grande (37-4 a.C.) a causa de la destrucción ocasionada por un incendio, un terremoto 0 ambos. Anteriormente, el denominado período la, sabemos que se instaló un pequeño grupo en los restos de una fortaleza de los siglos VIII-VII a.C., pero no tenemos constancia ni de que se tratara del mismo ni tampoco de que realmente formara una comunidad. De ser correcta nuestra tesis, la secta habria comenzado su existencia en el período $\mathrm{lb}$, durante el reinado de Juan Hircano y precisamente su articulación claramente comunitaria explicaría la distribución de los enclaves de una manera racional y definitiva.

\section{CONCLUSIÓN}

Los datos conocidos hasta la fecha ligados a los que aporta la publicación del documento denominado 4QMMT contribuyen a esclarecer alguno de los aspectos más oscuros de la historia de los sectarios del mar Muerto. En primer lugar, creemos que deberian descartarse de manera definitiva las identificaciones de la secta con fariseos, zelotes y judeo-cristianos. El origen de la secta fue saduceo, aunque el paso del tiempo la fuera radicalizando progresivamente hasta el punto de convertirla en un ente que ya poco contacto tenía con aquellos, salvo en aspectos formales.

En segundo lugar, también parece que se puede fijar, al menos aproximadamente, la fecha de surgimiento de la secta. De no ser ésta la señalada en este artículo, sólo pudo variar en un margen realmente estrecho de años si deseamos que encaje con los datos paleográficos, arqueológicos e históricos de que disponemos. Pero, en estos momentos, no creemos que se pueda pensar en una alternativa igual de convincente a la que proponemos.

En tercer lugar, nos parece que sigue sin demostrarse de manera tajante (aunque no puede negarse la posibilidad y, hoy por hoy, sea la más verosímil) que la secta del mar Muerto fueran los esenios. Ciertamente pudo ser así, pero también cabe la posibilidad de que éstos fueran 
anteriores ${ }^{35}$ a la secta del mar Muerto y que, posteriormente, se fusionaran con ésta o la influyeran de manera definitiva.

El documento 4QMMT parece, pues, desde nuestro punto de vista, concluir de manera definitiva la discusión en torno a los orígenes de la secta de Qumran. Su identificación final, tras las fases iniciales de su historia, sigue siendo, a nuestro juicio, aún materia abierta a la controversia.

${ }^{35}$ En este sentido y datando el origen de los esenios en el destierro de Babilonia, cf. Murphy-O'Connor, J., "The Essenes and their History", Revue Biblique, núm. 81, 1974, págs. 215-224, e idem, "The Essenes in Palestine", Biblical Archaeologist, núm. 40, 1977. págs. 100-124. 
BIBLIOGRAFIA

Baumgarten, J. M., "The Pharisaic-Sadducean Controversies about Purity and the Qumran Texts». Journal of Jewish Studies, núm. 31, 1980 , págs. $157-170$.

Cullmann, O., The Christology of the New Testament. Londres, SCM, 1975.

DELCOR, M., Le vocabulaire juridique, culturel et mystique de l'initiation dans la secte de Qumrân. Qumran. Probleme. Berlín, 1963, págs. 109-134.

Delcor, M., y Garcia Martínez, F., Introducción a la literatura esenia de Qumran. Madrid, Cristiandad, 1982.

DrIVER, G. R., The Judaean Scrolls. The Problem and a Solution. Oxford, 1965.

-: "Myths of Qumran". Annual of Leeds University Oriental Society, núm. 6, 1966-68, págs. 23-40.

-: "Mythology of Qumran», Jewish Quarterly Review, núm. 71, 1970, págs. 241-281.

Dupont-SOMmer, A., Les Écrits esséniens découverts près de la Mer Morte. París, 1959.

Fernández Uriel, P., y Vidal Manzanares, C., "Anavim, apocalípticos y helenistas" en Homenaje a José Maria Blázquez. Madrid (en prensa).

Friedner, Y., History of the Jewish people: The Second Temple Era. Nueva York, Mesorah, 1986.

Garcia Martínez, F., véase, Delcor, M. y García Martínez, F.

Gaster, T. H., The Dead Sea Scriptures. Nueva York, Anchor, 1976.

GinzBERG, L., "An Unknown Jewish sect», Moreshet, series núm. 1, Nueva York, 1976.

Gónzalez Lamadrid, A., Los descubrimientos del mar Muerto. Madrid, BAC, 1985. 
Grego, I., I Giudeo-Cristiani nel IV secolo. Jerusalén, FPP, 1982.

Habermann, A. M., Meguillot guenuzot mi-Midbar Yehudah. 1959, Tel Aviv (en hebreo).

Lagrange, J. M., "La secte juive de la Nouvelle Alliance au pays de Damas", Revue Biblique, núm. 9, 1912, págs. 321-330.

-: Le judaïsme avant Jésus-Christ. París, 1931.

LEVI, I., Revue des études juives, núm. 62, 1912.

Margoliouth, G., "The Two Zadokites Messiahs", Journal of Theological Studies, núm. 12, 1911, págs. 446-450.

Meeks, W. A., The Writings of St. Paul. Nueva York, W. W. Norton and Company, 1972.

MURPHY-O'ConNoR, J., "The Essenes and their History", Revue Biblique, núm. 81, 1974.

-: "The Essenes in Palestine", Biblical Archaeologist, núm. 40, 1977, págs. 100-124.

NORTH, R., "The Qumran Sadducees», Catholic Biblical Quarterly, núm. 17, 1955, págs. 164-188.

QuimRon, E. y StRUNGelL, J., "An Unpublished Halakhic Letter from Qumran», Biblical Archaeology Today, 1985, Jerusalén, Israel Exploration Society, págs. 400-407.

RaBIN, CH., Qumran Studies. Scripta Judaica II. Londres, 1957.

Roth, C., The Historical Background of the Dead Sea Scrolls. Oxford, 1958.

SCHIFFMAN, L. H., "The New Halkhic Letter (4QMMT) and the origins of the Dead Sea Sect", Biblical Archaeologist, junio 1990. Baltimore, págs. 64-73.

Strungell, J., véase Quimron, E., y Strungell, J.

SUKENIK, E. L., Meguillot genuzot mi-Midbar Yehudah. Jerusalén, Bialik, 1948 y 1950 (en hebreo).

TALMON, S., "The Calendar Reckoning of the Sect from the Judaean Desert», en The World of Qumran from within, 1989, Jerusalén, Magnes, págs. 157-185.

THIERING, B. E., "Redating the Teacher of Righteousness. Australian and New Zealand Studies", in Theology and Religion, núm. 1, Sydney, 1979.

VAuX, R. DE, Revue Biblique, núm. 64, 1957, págs. 636-736.

-: "Esséniens ou Zélotes? à propos d'un livre récent», Revue Biblique, núm. 73, 1966, págs. 212-235.

-: Archaeology and the Dead Sea Scrolls. Londres, Clarendon, 1973.

VERMÉS, G., Los manuscritos del mar Muerto. Barcelona, Muchnick, 1987.

Vidal Manzanares, C., véase, Fernández Uriel, P., y Vidal Manzanares, C. 
WIEDER, N., The Judaean Scrolls and Karaism. Londres, 1962.

WOUdE VAN DER, A. S., “De Tempelrod van Qumrân», Nederlands Theologisch Tijdschrift, núm. 34, 1980, págs. 177-190.

-: "Wicked Priest or Wicked Priests? Reflections on the Identification of the Wicked Priest", in the Habakkuk Commentary, núm. 32, 1982, págs. 349-359.

ZEITLIN, S., "The Zadokite fragments", Jewish Quarterly Review. Monograph Series, núm. 1, Filadelfia, 1952.

-: The Dead Sea Scrolls and Modern Scholarship. Filadelfia, 1956. 